Western University

Scholarship@Western

$10-2-2018$

\title{
Phosphonium hydrogels for controlled release of ionic cargo.
}

Tristan D Harrison

Paul J Ragogna

Elizabeth R Gillies

Follow this and additional works at: https://ir.lib.uwo.ca/chempub

Part of the Chemistry Commons

\section{Citation of this paper:}

Harrison, Tristan D; Ragogna, Paul J; and Gillies, Elizabeth R, "Phosphonium hydrogels for controlled release of ionic cargo." (2018). Chemistry Publications. 133.

https://ir.lib.uwo.ca/chempub/133 


\title{
ChemComm
}

\section{COMMUNICATION}

\section{Phosphonium hydrogels for controlled release of ionic cargo}

\author{
Tristan D. Harrison, ${ }^{a}$ Paul J. Ragogna, ${ }^{a *}$ and Elizabeth R. Gillies, ${ }^{a, b *}$
}

Received 00th January 20xx,

Accepted 00th January 20xx

DOI: $10.1039 / \times 0 \times x 00000 x$

www.rsc.org/

We describe the synthesis of three different phosphonium salts and their reaction with poly(ethylene glycol) dimethacrylate to create cationic hydrogels. The hydrogels were loaded with an anioinic dye and an anionc anti-inflammatory drug through ionic interactions and compared with an analogous ammonium gel. The release rates of these anions depended on their structure and $\mathrm{pK}_{\mathrm{a}}$ values, as well as the $\mathrm{pH}$ and ionic strength of the release medium.

Many traditional therapeutics suffer from limitations including side effects due to poor targeting, difficulty in controlling dosage and low patient compliance. ${ }^{1}$ These challenges emphasize the need for superior controlled drug delivery systems. There are various approaches to delivering therapeutics that can release molecules in a controlled manner, ensuring sustained delivery. ${ }^{2,3}$ The use of hydrogels, crosslinked networks containing a high fraction of water, is one of the commonly employed strategies. Hydrogels have been used in many applications such as wound dressings, ${ }^{4}$ ocular aids, ${ }^{5}$ and drug delivery. ${ }^{6}$ Their high water content, and soft, rubbery properties can minimize inflammatory reactions of surrounding cells and tissues, imparting high biocompatibility. ${ }^{7}$ In addition, they can be shaped and molded into many different structures that can be designed to match anatomical requirements. ${ }^{8}$

Many early examples of hydrogels involved relatively inert and non-functional polymers. For example, poly(ethylene glycol) (PEG) has been widely used in hydrogels because it has weak immunogenicity and is FDA approved in certain applications. ${ }^{9}$ Recently, newer classes of hydrogels including those based on peptides ${ }^{10}$ and those capable of responding to changes in conditions such as $\mathrm{pH}^{11}$ or temperature, ${ }^{12}$ to enable triggered drug release have been reported. The release of drugs

a. Department of Chemistry and The Centre for Materials and Biomaterials Research (CAMBR), The University of Western Ontario, 1151 Richmond St., London, Canada N6A 5B7. E-mail: egillie@uwo.ca

${ }^{b}$ Department of Chemical and Biochemical Engineering, The University of Western Ontario, 1151 Richmond St., London, Canada N6A 5B9

+Electronic Supplementary Information (ESI) available:

See DOI: 10.1039/x0xx00000x can be controlled through network degradation, ${ }^{13}$ mechanical deformation ${ }^{14}$ or swelling/shrinking. ${ }^{15}$ Alternatively specific interactions between the hydrogel and the drug can be incorporated, including covalent conjugation, ${ }^{16}$ hydrophobic associations ${ }^{17}$ or electrostatic interactions. ${ }^{18}$

Quaternary ammonium salts carry a positive charge at nitrogen and have been extensively studied as antimicrobial agents and electrostatic drug delivery vehicles. ${ }^{19,20}$ Quaternary phosphonium cations also carry positive charges at phosphorus but exhibit different charge distributions and have been shown to have enhanced performance over their ammonium counterparts in areas including antimicrobial activity ${ }^{21}$ and nucleic acid binding. ${ }^{22}$ While a limited number of phosphoniumcontaining hydrogels have been reported, ${ }^{23,24}$ to our knowledge they have not been investigated for drug delivery. In this context, we report phosphonium-containing hydrogels as controlled delivery vehicles. The phosphonium monomers can be cured using UV light to create stable cross-linked hydrogels through a simple process. The hydrogel properties and drug release rates can be tuned by varying the monomer structures.

First, tris(hydroxypropyl)phosphine, tri- $n$-butylphosphine and triphenylphosphine were reacted with 4-vinylbenzyl chloride to generate the corresponding polymerizable phosphonium salts $\mathbf{T}(\mathbf{h p})-\mathbf{P}, \mathbf{B u}-\mathbf{P}$, and $\mathbf{P h}-\mathbf{P}$, respectively (Scheme 1). These phosphonium derivatives were of specific interest because they have varying structures and hydrophobicities, potentially allowing their interactions with molecules in the hydrogels to be tuned. Tri- $n$-butyl(4vinylbenzyl)ammonium chloride (Bu-N) was also investigated to enable comparison between phosphorus and nitrogen

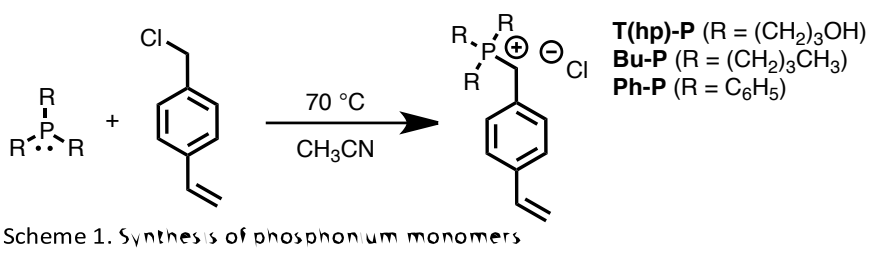




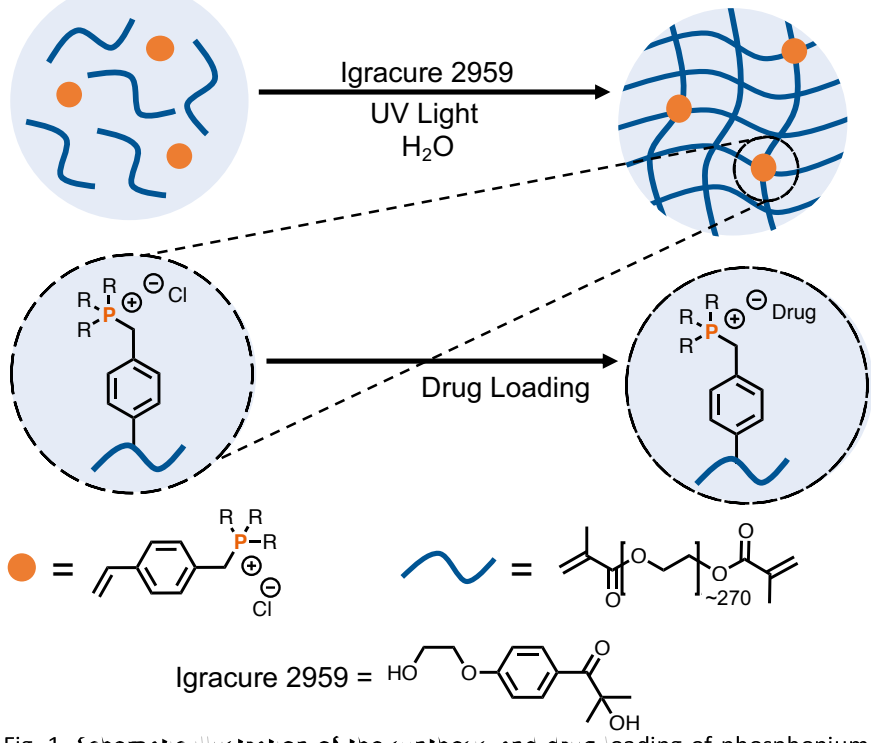

Fig. 1. Schemalc ustrat on of the svnthess and drug oading of phosphonium hydrogels.

analogues. PEG dimethacrylate (PEGDMA) with an $\mathrm{M}_{\mathrm{n}}$ of 11,900 $\mathrm{g} / \mathrm{mol}$ was incorporated to provide cross-linking. The hydrogels were prepared from water-based formulations containing 89 wt\% PEGDMA, 10 wt\% onium salt (T(hp)-P, Bu-P, Ph-P and BuN) and 1 wt\% photoinitiator (Igracure 2959; Fig. 1). Formulations were transferred to round Teflon $\AA$ molds, purged with $\mathrm{N}_{2}$ then cured by irradiation with UV light for $30 \mathrm{~min}$.

The gel content was similar for the different phosphonium networks, ranging from $71-74 \%$, while the ammonium network had a higher gel content of $92 \%$ (Table 1 ). Dried hydrogels were then placed into either deionized (DI) $\mathrm{H}_{2} \mathrm{O}$ or into citric acid/sodium phosphate buffer with $\mathrm{pH}$ of 5,6 or 7.4 and the hydrogels were swelled at $37^{\circ} \mathrm{C}$. Swelling occurred over 2-6 $\mathrm{h}$ for each system (Fig. S9). In each case, the swelling was highest in DI water, ranging from 1170 to $3700 \%$ of the dry weight. The swelling capacity was highest in pure $\mathrm{H}_{2} \mathrm{O}$ due to the osmotic pressure. Conversely, when the hydrogels were placed into salt solutions, the osmotic pressure was much lower, resulting in less swelling. ${ }^{25}$ Swelling varied slightly with $\mathrm{pH}$ due to the different buffer compositions (Table S1). ${ }^{26}$ Swelling was highest for the T(hp)-P hydrogel, followed by Bu-P, and was lowest for $\mathbf{P h}-\mathbf{P}$ and $\mathbf{B u}-\mathbf{N}$, correlating with the decreasing hydrophilicities of the phosphonium salts and suggesting differences between the $\mathrm{P}$ and $\mathrm{N}$-based gels perhaps due to their different gel contents. SEM confirmed the microporous structures of all of the gels (Fig. S10). T(hp)-P and Bu-P gels appeared to have the largest pores, which correlated with their higher degrees of swelling. Based on thermogravimetric analysis, all of the phosphonium-based networks had decomposition temperatures of $\sim 240{ }^{\circ} \mathrm{C}$, whereas the Bu-N network decomposed at $180^{\circ} \mathrm{C}$.

To explore the abilities of the hydrogels to load anionic molecules and release them in a controlled manner, each hydrogel was first loaded with fluorescein sodium salt, an anionic dye. Loading was performed by immersing the hydrogels in a 1 wt\% fluorescein sodium salt solution for $24 \mathrm{~h}$. The gels were then washed in DI water to release all non-
Table 1. Swelling percentages, gel content and loading capacities of hydrogels.

\begin{tabular}{|c|c|c|c|}
\hline Hydrogel & Swelling (\%) & $\begin{array}{c}\text { Gel Content } \\
\text { (\%) }\end{array}$ & $\begin{array}{c}\text { Loading } \\
\text { Capacity } \\
(\%)^{a}\end{array}$ \\
\hline$T(h p)-P$ & $\begin{array}{c}\text { DI Water: } 3700 \pm \\
1100 \\
\text { pH 5: } 1560 \pm 12 \\
\text { pH 6: } 1550 \pm 33 \\
\text { pH 7.4: } 1360 \pm 75\end{array}$ & $73 \pm 0.2$ & $\begin{array}{c}\text { Fluorescein: } \\
0.77 \pm 0.03 \\
\text { Diclofenac: } \\
3.9 \pm 0.06\end{array}$ \\
\hline Bu-P & $\begin{array}{c}\text { DI Water: } 2290 \pm 240 \\
\text { pH 5: } 1510 \pm 170 \\
\text { pH 6: } 1460 \pm 98 \\
\text { pH 7.4: } 1260 \pm 130\end{array}$ & $71 \pm 2$ & $\begin{array}{c}\text { Fluorescein: } \\
0.60 \pm 0.03 \\
\text { Diclofenac: } \\
3.8 \pm 0.08\end{array}$ \\
\hline Ph-P & $\begin{array}{c}\text { DI Water: } 1750 \pm 340 \\
\text { pH 5: } 870 \pm 26 \\
\text { pH 6: } 880 \pm 33 \\
\text { pH 7.4: } 800 \pm 33\end{array}$ & $74 \pm 1$ & $\begin{array}{c}\text { Fluorescein: } \\
0.71 \pm 0.08 \\
\text { Diclofenac: } \\
4.1 \pm 0.34\end{array}$ \\
\hline Bu-N & $\begin{array}{c}\text { DI Water: } 1170 \pm 170 \\
\text { pH 5: } 760 \pm 65 \\
\text { pH 6: } 770 \pm 17 \\
\text { pH 7.4: } 750 \pm 60\end{array}$ & $92 \pm 1$ & $\begin{array}{l}\text { Fluorescein: } \\
3.2 \pm 0.27 \\
\text { Diclofenac: } \\
15 \pm 2\end{array}$ \\
\hline
\end{tabular}

$a \%$ relative to one gram of dry hydrogel

ionically bound fluorescein until no further dye was detected in the washings (Fig. S11A). A control hydrogel based only on PEGDMA was also evaluated. It was found that the oniumcontaining gels retained a deep red color after the washing procedure, while the PEGDMA gel did not retain any detectable dye (Fig. S12). This indicated that anionic molecules could be retained in the onium-based networks. The ionically bound dye could be released from the hydrogels by immersion in a $1 \mathrm{wt} \%$ solution of cetyltrimethylammonium chloride (CTAC), allowing the amount of bound dye to be calculated as loading capacity (Table 1). The Bu-N gel released much more unbound dye during the washing compared with the phosphonium gels. However, it also retained a higher loading after the washing.

To measure the release rates under different conditions, each fluorescein-loaded hydrogel was placed into either DI water or buffered solutions at $\mathrm{pH} 5,6$ or 7.4 at $37^{\circ} \mathrm{C}$. The release rate of fluorescein was fastest from the $\mathbf{T}(\mathbf{h p})-\mathbf{P}$ hydrogels in all buffers, with complete release over $24 \mathrm{~h}$, likely due to their high hydrophilicity and high degree of swelling (Fig. 2A). In contrast, $\mathbf{P h}-\mathbf{P}$ hydrogels released the fluorescein much more slowly, over at least $100 \mathrm{~h}$ (Fig. 2B and S13C). This can be attributed to the lower degree of swelling of this gel, which would slow diffusion of molecules out of the network. Furthermore, the phenyl groups on the phosphonium cation may interact with fluorescein through $\pi$ stacking and van der Waals forces in addition to ionic interactions. Despite their different degrees of swelling, the Bu-P and Bu-N hydrogels exhibited similar fluorescein release rates in buffers and they were intermediate between those of the other phosphonium hydrogels (Fig. S13B,D).

The release rates also depended on the $\mathrm{pH}$, with fastest release at $\mathrm{pH} 7.4$ and slowest release at $\mathrm{pH} 5$ (Fig. 2A,B and S13). Although the swelling was slightly lower at $\mathrm{pH} 7.4$ than at the other $\mathrm{pH}$ values, which would favour slower release, the 

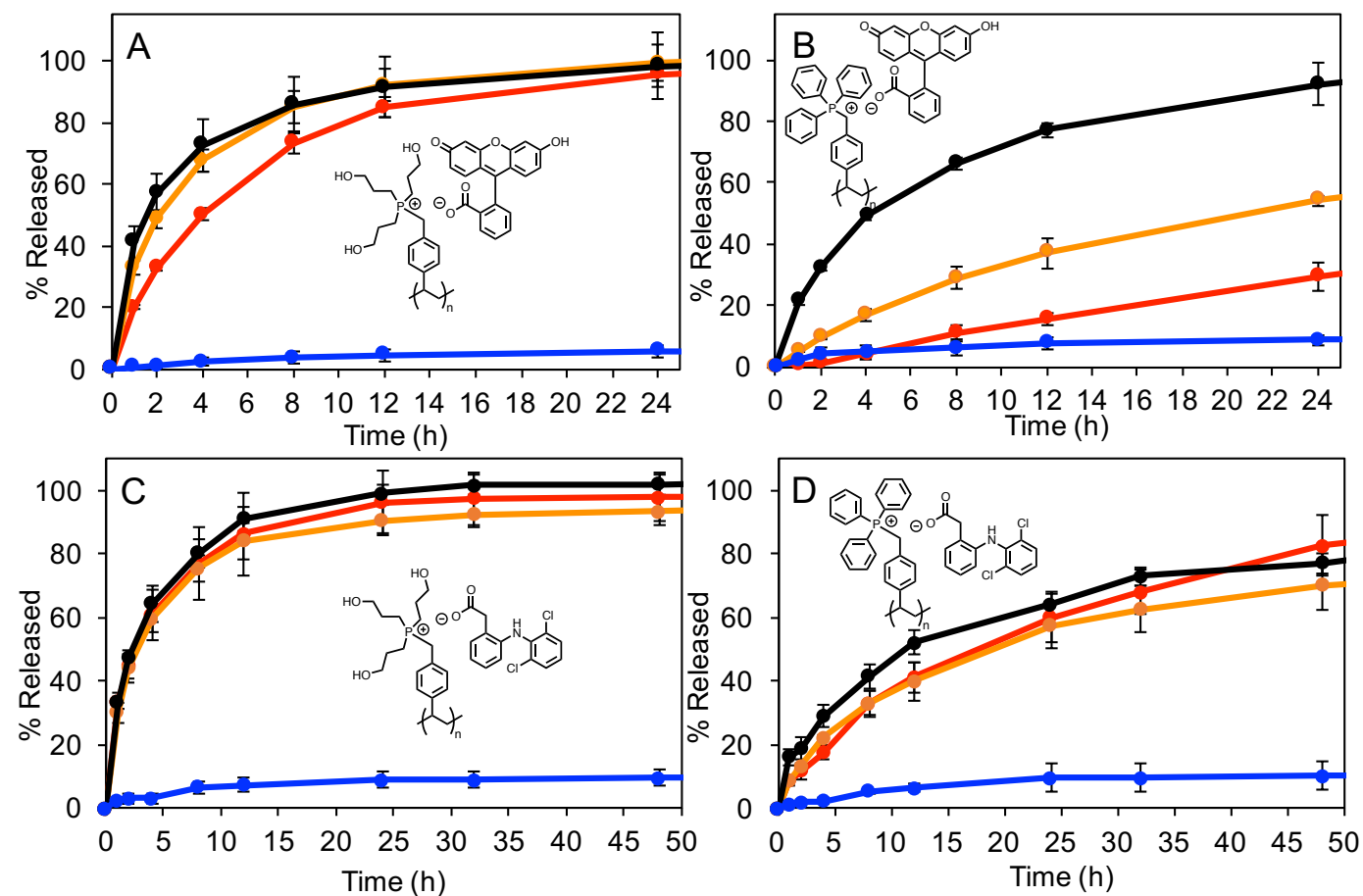

Fig.2. Release rates of: A) fluorescein from T(hp)-P hydrogels; B) fluorescein from Ph-P hydrogels; C) diclofenac from $\mathbf{T}(\mathbf{h p})-\mathbf{P}$ hydrogels; D) diclofenac from Ph-P hydrogels (Blue line $-\mathrm{DI}$ Water, $\mathrm{Red}-\mathrm{pH}=5$, Orange $-\mathrm{pH}=6, \mathrm{Black}-\mathrm{pH}=7.4$ )

behaviour was dominated by the protonation state of fluorescein. Fluorescein has a pKa value of $6.7,27$ and as the $\mathrm{pH}$ of the solution was decreased from $\mathrm{pH} 7.4$ to $\mathrm{pH} 5$, the molecule became less anionic, and consequently more hydrophobic. This favoured its retention in the hydrogel and slowed its release. Finally, although the hydrogels swelled much more in DI water than in the buffer solutions, the release in DI water was much slower for hydrogels $\mathbf{T}(\mathbf{h p})-\mathbf{P}, \mathbf{B u}-\mathbf{P}, \mathbf{P h}-\mathbf{P}$, as there were no anions to exchange with the fluorescein to enable its release. However, the release of fluorescein from the Bu-N hydrogel was much faster than from any of the phosphonium gels in DI water (Fig. S13D). Thus, the release rate depended on the ion structure as well as the $\mathrm{pH}$ and the presence of salt.

The loading and release of the non-steroidal antiinflammatory drug diclofenac were then investigated. Notably, the loading capacities of the gels for diclofenac were $\sim 5$-fold higher than for fluorescein (Table 1), which may result from its higher hydrophobicity or the presence of a single ionizable site compared to fluorescein which can undergo multiple deprotonation events. The release of diclofenac from the hydrogels was then studied under the same conditions described above. As for fluorescein, T(hp)-P hydrogels released diclofenac most rapidly, with release complete in $24 \mathrm{~h}$ (Fig. 2C). Bu-P, Ph-P and Bu-N hydrogels released diclofenac more slowly, with complete release requiring $\sim 120 \mathrm{~h}$ (Fig. 2D, S14). Like for fluorescein, the release of diclofenac from the Bu-N gel was much faster than from the other gels in DI water, suggesting that there may have been more non-specific binding of the drug in the Bu-N gel (Fig. S14D). However, unlike fluorescein, the release rates were not very dependent on the $\mathrm{pH}$ for any system. The $\mathrm{pK}_{\mathrm{a}}$ value for diclofenac is reported to be $4.1,{ }^{28}$ so it should remain primarily in its anionic state from $\mathrm{pH}$ 5-7.4. Lowering of the $\mathrm{pH}$ to 4 resulted in visible precipitation of diclofenac in the hydrogel. Thus, the $\mathrm{pH}$-dependent release of drugs from the network depends on their specific chemical structures and $\mathrm{pK}_{\mathrm{a}}$ values. Loading of an amino acid, tryptophan, was also attempted in deionized water, but due to its isoelectric point at 5.89 , it existed predominately in its neutral form upon loading. When washed with water, all of the tryptophan was rapidly released (Fig. S11C).

The growth of $\mathrm{C} 2 \mathrm{C} 12$ mouse myoblast cells on the hydrogels was also studied. The hydrogels were seeded with $\mathrm{C} 2 \mathrm{C} 12$ cells, incubated for $2 \mathrm{~h}$, then washed to remove unadhered cells. After $72 \mathrm{~h}$, the cells were fixed and stained with 4',6-diamidino2-phenylindole (DAPI, blue, cell nuclei) and Alexa Fluor 568 (cytoskeletons, red). The glass slide (control) was an excellent substrate for cell attachment and proliferation (Fig. 3A). The cells appeared healthy with normal cytoskeletons and were well spread over the entire surface. In contrast, for each of the T(hp)$\mathbf{P}, \mathbf{B u}-\mathbf{P}$, and $\mathbf{P h}-\mathbf{P}$ hydrogels, no cells were detected on the
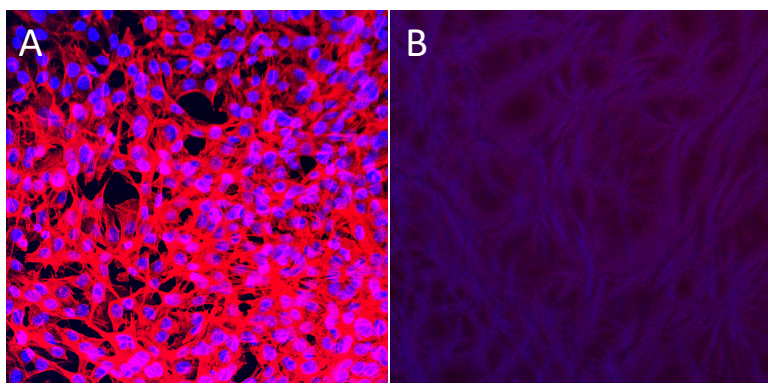

Fig. 3. Confocal microscopy images of $\mathrm{C} 2 \mathrm{C} 12$ cells adhered to A) glass slide (control); B) T(hp)-P hydrogel (only weak autofluorescence of the gel was observed). The cell nuclei were stained blue and cytoskeletons were stained red. Each image represents an area of $0.45 \times 0.45 \mathrm{~mm}$. 
surfaces (Fig. 3B, S15). To probe this further, the hydrogels were immersed in cell culture medium, then this medium was added to $\mathrm{C} 2 \mathrm{C} 12$ cells. High cell viability was retained for each gel, as indicated by -(4,5-dimethylthiazol-2-yl)-2,5-diphenyltetrazolium bromide (MTT) assays (Fig. S16), suggesting that the gels did not leach toxic species that would prevent the growth of cells. We also investigated the toxicities of the onium monomers using MTT assays and found that it was dependent on the monomer structure. Greater than $80 \%$ viability was observed for $\mathbf{T}(\mathbf{h p})$-P up to $1 \mathrm{mg} / \mathrm{mL}$, whereas the other monomers exhibited toxicity at much lower concentrations (Fig. S17). The fact that resistance to cell adhesion occurred for all gels, regardless of monomer structure suggests that adhesion properties were dominated by the high PEG content, as PEG is known to resist protein adsorption and consequently cell adhesion. ${ }^{29}$ However, it is also possible that direct contact between cells and monomers covalently incorporated into the gels played a role.

In conclusion, we have developed a new method for incorporating phosphonium cations into PEG based hydrogels to enable the ionic entrapment of anionic dyes and drug molecules. The hydrogel formation was completed rapidly and efficiently using UV light. The initial work to load anionic dyes and drug molecules has shown that the release rates can be tuned based on the chemical structures of the phosphoniums and anions, as well as the ionic strength and $\mathrm{pH}$ of the release medium. No growth of $\mathrm{C} 2 \mathrm{C} 12$ cells was observed on the hydrogel surfaces, suggesting that they may resist fouling in biological systems.

\section{Conflicts of Interest}

There are no conflicts to declare.

\section{Acknowledgements}

We thank the Natural Sciences and Engineering Research Council of Canada (Discovery, CRD and SPG grants to PJR and ERG), Solvay, and the University of Western Ontario for funding this work. Aneta Borecki and lan Villamagna are thanked for help with the cell work and SEM respectively.

\section{Notes and references}

1 R. Langer, Nature, 1998, 392, 5-10.

2 R. Tong, H. D. Hemmati, R. Langer and D. S. Kohane, J. Am. Chem. Soc., 2012, 134, 8848-8855.

3 P. G. Lawrence, P. S. Patil, N. D. Leipzig and Y. Lapitsky, ACS Appl. Mater. Interfaces, 2016, 8, 4323-4335.

4 P. Mostafalu, G. Kiaee, G. Giatsidis, A. Khalilpour, M. Nabavinia, M. R. Dokmeci, S. Sonkusale, D. P. Orgill, A. Tamayol and A. Khademhosseini, Adv. Funct. Mater., 2017, 1702399, 1-10.

5 Z. Zhang, Z. He, R. Liang, Y. Ma, W. Huang, R. Jiang, S. Shi, H. Chen and X. Li, Biomacromolecules, 2016, 13, 798-807.

6 S. J. Buwalda, T. Vermonden and W. E. Hennink, Biomacromolecules, 2017, 18, 316-330.
7 J. I. Kroschwitz and H. F. Mark, Encyclopedia of Polymer Science and Technology, Wiley-Interscience, Hoboken, New Jersey, 2003.

8 J. Li and D. J. Mooney, Nat. Rev. Mater., 2016, 1, 1-18.

9 C. C. Lin and K. S. Anseth, Pharm. Res., 2009, 26, 631-643.

10 Z. Yu, Q. Xu, C. Dong, S. Lee, L. Gao, Y. Li, M. D'Ortenzio and J. Wu, Curr. Pharm. Des., 2015, 21, 4342-4354.

11 S. Zhang, A. M. Bellinger, D. L. Glettig, R. Barman, Y. A. L. Lee, J. Zhu, C. Cleveland, V. A. Montgomery, L. Gu, L. D. Nash, D. J. Maitland, R. Langer and G. Traverso, Nat. Mater., 2015, 14, 1065-1071.

12 H. Dai, Q. Chen, H. Qin, Y. Guan, D. Shen, Y. Hua, Y. Tang and J. Xu, Macromolecules, 2006, 39, 6584-6589.

13 T. M. O'Shea, A. A. Aimetti, E. Kim, V. Yesilyurt and R. Langer, Adv. Mater., 2014, 27, 65-72.

14 N. Huebsch, C. J. Kearney, X. Zhao, J. Kim, C. A. Cezar, Z. Suo and D. J. Mooney, Proc. Natl. Acad. Sci., 2014, 111, 97629767.

15 R. J. Mumper, A. S. Huffman, P. A. Puolakkainen, L. S. Bouchard and W. R. Gombotz, J. Controlled Release, 1994, 30, 241-251.

16 S. Traub, J. Morgner, M. M. Martino, S. Höning, M. A. Swartz, S. A. Wickström, J. A. Hubbell and S. A. Eming, Biomaterials, 2013, 34, 5958-5968.

17 T. R. Thatiparti, A. J. Shoffstall and H. A. von Recum, Biomaterials, 2010, 31, 2335-2347.

18 N. J. Shah, M. N. Hyder, M. A. Quadir, N.-M. Dorval Courchesne, H. J. Seeherman, M. Nevins, M. Spector and P. T. Hammond, Proc. Natl. Acad. Sci., 2014, 111, 12847-12852.

19 S. Q. Liu, C. Yang, Y. Huang, X. Ding, Y. Li, W. M. Fan, J. L. Hedrick and Y. Y. Yang, Adv. Mater., 2012, 24, 6484-6489.

20 N. Peng, Y. Wang, Q. Ye, L. Liang, Y. An, Q. Li and C. Chang, Carbohydr. Polym., 2016, 137, 59-64.

21 A. Kanazawa, T. Ikeda and T. Endo, J. Polym. Sci. Part A Polym. Chem., 1993, 31, 335-343.

22 S. T. Hemp, M. H. Allen, M. D. Green and T. E. Long, Biomacromolecules, 2012, 13, 231-238.

23 T. Watanabe, M. Utsunomiya, S. Kurihara and T. Nonaka, J. Polym. Sci., Part A: Polym. Chem., 2001, 39, 1505-1514.

24 C. Chung, K. J. Lampe and S. C. Heilshorn, Biomacromolecules, 2012, 13, 3912-3916.

25 N. V. Gupta and H. G. Shivakumar, Iran. J. Pharm. Res., 2012, 11, 481-493.

26 Y. Kohno, D. Gin, R. D. Noble and H. Ohno, Chem. Commun., 2016, 52, 7497-7500.

27 M. J. Doughty, Ophthalmic Physiol. Opt., 2010, 30, 167-174.

28 C. M. Adeyeye and P.-K. Li, Anal. Profiles Drug Subst., 1990, 19, 123-144.

29 J. M. Harris and S. Zalipsky, Poly(ethylene glycol) Chemistry and Biological Applications, American Chemical Society, Washington, 1997. 